\title{
A prospective Study of the Risk of Depression in Acne Patients Treated with Oral Isotretinoin \\ Rabie Bedir Atallahb ${ }^{1}$, Hany Othman Abo Alwafa ${ }^{1}$, Mohamed Abdel Fattah El Mahdy ${ }^{2}$, Asmaa Elsayed Mahmoud ${ }^{3}$ \\ ${ }^{1}$ Dermatology, Venereology and Andrology Department, ${ }^{2}$ Psychatric Department, Faculty of Medicine, Al-Azhar University, Damietta, Egypt, ${ }^{3}$ Dermatology Department, Damanhour National Medical Institute \\ Corresponding author: Asmaa Elsayed Mahmoud, Mobile: 01003407130; Email:dr_snowwhite1234@yahoo.com
}

\begin{abstract}
Background: depression showed up as potential side effect of isotretinoin in the summary of product characteristics. There have been numerous studies treating this issue yet as a rule not distinguishing any significant depression or suicide risk.

Aim of the Work: this study aimed to evaluate the risk of depression in acne patients treated with oral isotretinoin therapy. Methods: one hundred patients with moderate to severe acne were enrolled in noncontrolled prospective study. The psychological condition was evaluated at the baseline and fourth month by the Hamilton Depression Rating Scale (HDRS) for all patients. Statistical analysis of HDRS scores was performed. Results: all patients completed the study. Before the treatment $18 \%$ of the patients had suffered from mild depressive symptoms. at end of 4 months The patient's scores remained below the subclinical level for depression except only 2 patients one was mildly depressed turned to moderately depressed after four months treatment with isotretinoin other was mildly depressed and still mildly depressed after four months treatment with isotretinoin. The incidence of depression was $1 \%$. Symptoms of depression which occurred in two patients, in which case coexisting situational factors were found to be the cause. Conclusion: our results showed that the oral isotretinoin treatment for acne at the typical therapeutic dose caused significant reduction in depression scores with a depression incidence only $1 \%$. These changes might be related to clinical effect of isotretinoin. Moreover, the treatment of acne improved symptoms of depression for most patients.
\end{abstract}

Keywords: Acne valgaris, systemic isotretinoin, depression.

\section{INTRODUCTION}

Due to its brilliant anti-acne effect, isotretinoin is the first choice of treatment for severe acne or moderate acne not responding to topical and or oral antibiotic (1). The relationship between isotretinoin treatment for acne and depression stays controversial both clinically and experimentally ${ }^{(2)}$.

\section{AIM of the WORK}

The aim of the study was to evaluate the risk of depression in acne patients treated with oral isotretinoin therapy.

\section{Materials and Methods:}

The participants in the study were recruited between September 2017 and September 2018 among attendants of Department of Dermatology and Venereology Outpatient Clinic Damietta Al-Azhar University Hospital. Male and female patients aged $\geq 12$ years who were suffering from moderate to severe acne was eligible to participate. At the screening assessment, patients completed medical histories were recorded, and routine physical and laboratory examinations were performed.
Before the oral administration of isotretinoin (at baseline), the severity of acne was assessed by grading, clinical photographs, and physical dermatological examination. Grading was performed according to Global Acne Grading scale. Details of any psychiatric history (Psychiatric diagnoses and/or treatment by a psychiatrist or psychologist) were recorded. The psychiatric status of patients was determined by using questions about depression, anxiety and psychological responses to acne. Participants completed the Hamilton Depression Rating Scale (HDRS). All questionnaires were checked by a psychiatrist. HDRS gave a rating of depression and changes in violent behavior of the patient. Scoring was based on the 17-item scale and scores of $0-7$ were considered as being normal, 8-13 suggested mild depression, 14-18 moderate depression and scores over 19-23 are indicative of severe depression $\geq 23$ indicative for very severe depression. Although the HRDS form lists 21 items the scoring was based on the first 17 to assess severity of depression. 
Isotretinoin was administered at a mean dose of $0.5 \mathrm{mg} / \mathrm{kg}$ per day. All participants and their parents were informed about the possibility of depression and were asked to report any depressive symptoms without delay. Participants or their parents signed written informed consent. Follow-up visits were carried out at one-month intervals until the isotretinoin treatment concluded. During each check-up, acne severity was assessed, and patients were asked about their psychological responses to acne and about any side effects of isotretinoin therapy, including depression, anxiety, and suicidal ideation At month 4 (the final month of isotretinoin therapy for some patients), participants completed the HDRS questionnaire. Total scores were assessed and again, all questionnaires were checked by a psychiatrist.

\section{STATISTICAL ANALYSIS}

Data were collected, summarized and reported on data collection sheets. Data was reentered into computer Microsoft Excel sheets with appropriate tabulation and graphical presentation. IBM SPSS software package version 20.0.Qualitative data were described using number and percent. The KolmogorovSmirnov test was used to verify the normality of distribution. Quantitative data were described using range (minimum and maximum), mean, standard deviation and median. Tests of significance (Chi square, Wilcoxon signed ranks test, Mann-Whitney's test, Monte Carlo correction, Pearson coefficient and Simple correlation coefficient) were used. Data were presented and suitable analysis was done according to the type of data. P-values less than $0.05(5 \%)$ was considered to be statistically significant.

\section{RESULTS \\ Baseline data}

A total of 100 patients were included in the study, of whom $35(35 \%)$ were male and 65 $(65 \%)$ were female. The mean age of the patients was $22.47 \pm 5.64$ years (range: 16-35 years). At baseline, 85 patients $(85 \%)$ patients were found to suffer from moderate acne, $(15 \%)$ with severe acne. The duration of the condition ranged from 1 to 10 years with mean of 3.7. All patients received $0.5-1.00 \mathrm{mg} / \mathrm{kg} /$ day of isotretinoin for a period not less than 16 weeks. According to the Hamilton Depression Rating Scale (HDRS) at baseline they were 82 patients $(82 \%)$ were normal and 18 patients (18\%) were mildly depressed. All patients completed the study.

\section{After 4 months treatment data}

At end of 4 months treatment of daily dose $(0.5-1 \mathrm{gm} . / \mathrm{kg})$ isotretinoin 87 patients $(87 \%)$ were complete cured (asymptomatic with no visible lesions) and 13 patients $(13 \%)$ were partially cured. When HDRS repeated at end of 4 months 98 patients $(98 \%)$ turned to normal and only 1 patient were (1\%) mildly depressed and another 1 patient (1\%) were moderately depressed (table 1). A statistically significant difference was observed between acne patients HDRS scores at baseline and at end of 4 month treatment with isotretinoin. The mean score significantly decreased at end of 4 month treatment with isotretinoin (Table 2).

Table 1: distribution of the studied cases according to depression $(n=100)$

\begin{tabular}{|l|l|l|l|l|l||}
\hline \multirow{2}{*}{ Depression } & \multicolumn{2}{|l|}{ Baseline } & \multicolumn{2}{l|}{ At the end 4 months } & \multirow{2}{*}{ MHp } \\
\cline { 2 - 5 } & No. & $\%$ & No. & $\%$ & \\
\hline Normal & 82 & 82.0 & 98 & 98.0 & \\
Mild & 18 & 18.0 & 1 & 1.0 & $<0.001^{*}$ \\
Moderate & 0 & 0.0 & 1 & 1.0 & \\
\hline
\end{tabular}

Table 2: descriptive analysis of the studied cases according to HDRS ( $\mathrm{n}=100)$

\begin{tabular}{|l|l|l|l|l||}
\hline HDRS & Baseline & At the end 4 months & Z & P \\
\hline Min. - Max. & $5.0-13.0$ & $3.0-15.0$ & & \\
Mean \pm SD. & $6.96 \pm 1.68$ & $5.87 \pm 1.35$ & $5.885^{*}$ & $<0.001^{*}$ \\
Median & 7.0 & 6.0 & & \\
\hline
\end{tabular}

Factors affect final HDRS results
- Severity of acne at baseline 
A statistically significant difference was observed between severity of acne and HDRS scores at baseline before starting isotretinoin. At baseline the mean score of patient with moderate acne is lower than mean score of patient with severe acne.

- Result of treatment acne patient by systemic isotretinoin after 4 months
A statistically significant difference was observed between HDRS scores and results of treatment acne patients with isotretinoin at end of 4 months. At the end of month 4 the mean score of cured patients was lower than the mean score of partially cured patients (Fig.1).

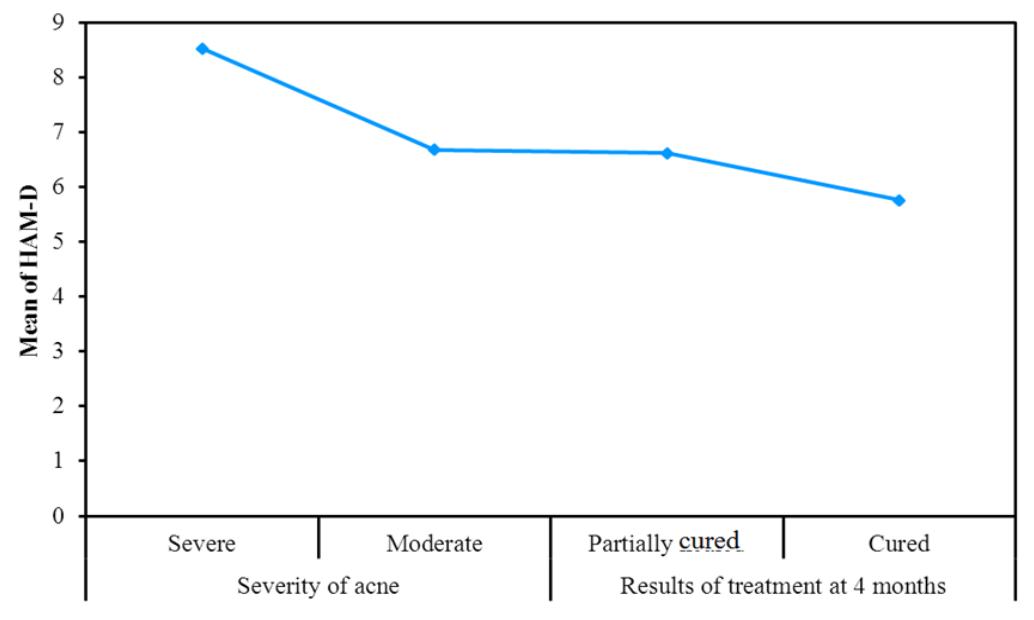

Figure 1: relation between depression represented by HDRS scores and acne course during 4 month treatment of isotretinoin $(n=100)$.

\section{DISCUSSION}

Recent reviews of the medical literature (3-13) had not sufficiently discovered proof to build up a causal link between isotretinoin use and depression, except for two studies (14,15) have suggested that isotretinoin had a causal link with depression. The present study aimed to measure risk of depression in acne patient treated with oral isotretinoin. The mean age of the patients who participated in this study was 22.47 $\pm 5.64 \mathrm{SD}$ with median 21 age years. Most were in their early 20s. According to an FDA report, the age range of the 37 patients that committed suicide was 13-32 years and the median age 17 years ${ }^{(\mathbf{1 6})}$. Therefore, with regard to age of participants, our study sample was regarded as being appropriate for investigating the relationship between oral isotretinoin therapy and psychiatric symptoms like depression or suicide.

According to a statistical expert opinion, the sample size of (100 patients) was considered to be representative in relation to other studies had similar sample size (100 patients) ${ }^{\mathbf{( 1 7 - 2 1 )}}$ or lower numbers of patients ${ }^{\mathbf{( 2 2}-}$ 24) .To test cognitive, affective, and somatic symptoms of depression, we used the Hamilton Depression Rating Scale (HDRS), with 17 item version. The HDRS had also been used in other studies $^{(4,20,26)}$ with good results.Regarding the optimal time for assessment depressive changes in acne patients treated with isotretinon Bremner and his colleagues suggested that depression usually develops 1-2 months or sometimes around 2-4 months after treatment ${ }^{(15)}$. In the present study the depression scores significantly decrease after 4 months except only one patient. This finding is similar to other studies ${ }^{(23,26,27)}$.

In the current prospective study oral isotretinoin treatment for acne at the typical therapeutic dose caused a significant reduction in depression scores with a depression incidence only $1 \%$. These changes might be related to improvement of acne lesions as a result of treatment by systemic isotretinoin. Moreover some patients might be more prone to depression regardless of acne or other conditions. The results are similar to other controlled studies ${ }^{28,29}$ and uncontrolled studies (22-26,27,30-32).

In the present study, $87 \%$ of patients were completely cured and therefore very satisfied with their appearance. $13 \%$ of patients were still had acne described as partially cured 
category. At the end of month 4 the mean score of HRDS of cured patients was lower than the mean score of partially cured patients. This result is in line with studies of many authors $(29,33,34)$. In the present study, moderate depression was developed in a single patient (1\%). The 21-yr.-old female's score increased from 13 (mild depression) to 15 (moderate depression) at month 4 of treatment. The psychiatric evaluation identified lack of interest, feeling guilty about the past, difficulty going to sleep, waking up early in the morning, mild disturbance of menstruation, preoccupation with health and slowed-down thinking and speech. There were no somatic symptoms, agitation, or suicidal thoughts. A diagnosis of moderate depression was made with these findings. Although the patient used isotretinoin for four months at this stage, she was very worried about the acne lesions continuing and new lesions appearing. She believed that her hopelessness was due to not experiencing the improvement in her acne lesions she had expected, and she therefore wanted to continue the treatment.The treatment was continued and all lesions had healed completely by the end of the seventh month. The depression score also decreased to 7 at the end of the treatment.

Mild depression was still presented in a single patient (1\%). The 27-yr.-old female's score decreased from 13 (mild depression) to 8 (mild depression) at month 4 of treatment which mean that the depression risk was lower than the baseline. The psychiatric evaluation productivity decreased, agitation, difficulty going to sleep, waking during night, waking up early in the morning. There were no symptoms depressed mood, somatic symptoms or suicidal thoughts. A diagnosis of mild depression was made with these findings, the patient was very happy for the end result of 4 month treatment with isotretinoin as almost all acne lesions was disappeared and patient clinically cured. Depressive symptoms thought to be caused by coexisting psychosocial stressors unrelated to acne.

\section{REFERENCES}

1. Terzi E, Tursen B and Tursen U (2017): Comparison of intermittent and standard isotretinoin treatment in moderate and severe Acne valgaris cases. Romanian Journal of Clinical and Experimental Dermatology,4:2-9.
2. Huang Yand Cheng C (2017): Isotretinoin treatment for Acne and risk of depression: A systematic review and metaanalysis. J. Am. Acad. Dermatol., 12:2-8.

3. Jick SS, Kremers HM and VasilakisScaramozza C (2000): Isotretinoin use and risk of depression, psychotic symptoms, suicide and attempted suicide. Arch. Dermatol., 136: 1231-1236.

4. Hull PR and D'Arcy C (2003): Isotretinoin use and subsequent depression and suicide: presenting the evidence. Am. J. Clin. Dermatol., 7: 493-505.

5. Hersom K, Neary MP, Levaux HP et al. (2003): Isotretinoin and antidepressant pharmacotherapy: a prescription sequence symmetry analysis. J. Am. Acad. Dermatol., 49: 424-432.

6. O'Donell J (2003): Overview of existing research and information linking isotretinoin (Accutane), depression, psychosis, and suicide. Am. J. Ther., 10:148-159.

7. Jacobs DG, Deutsch NL and Brewer M (2001): Suicide, depression and isotretinoin: is there a causal link. J. Am. Acad. Dermatol., 45: 168-175.

8. Ng CH and Schweitzer I (2003): The association between depression and isotretinoin use in Acne. Aust. NZ. J. Psychiatry, 37: 78-84.

9. Enders SJ and Enders JM (2003): Isotretinoin and psychiatric illness in adolescents and young adults. Ann. Pharmacother., 37: 1124-1127.

10. Marqueling AL and Zane LT (2005): Depression and suicidal behavior in acne patients treated with isotretinoin: a systematic review. Semin. Cutan. Med. Surg., 24: 92-102.

11. Strahan JE and Raimer $S$ (2006): Isotretinoin and the controversy of psychiatric adverse effects. Int. J. Dermatol., 45: 789-799.

12. Gupta M and Gupta AK (2008): Nearly 10 million visits show no link between isotretinoin use and suicide. $66^{\text {th }}$ Annual Meeting of the American Academy of Dermatology, San Antonio, pp: 1-5.

13. Dreno $B$ and Chosidow O (2008): Isotretinoin and psychiatric effects: facts and hypothesis. Expert. Rev. Dermatol., 6: 711-720.

14. Azoulay L, Blais L, Koren $G$ and $e t$ al. (2008): Isotretinoin and the risk of 
depression in patients with Acne vulgaris: a casecrossover study. J. Clin. Psychiatry, 69: 526-532.

15. Bremner J, Shearer $K$ and McCaffery $P$ (2012): Retinoic acid and affective disorders: the evidence for an association. J. Clin. Psychiatry, 73: 37-50.

16. Wysowski D, Pitts M and Beitz J (2001): Depression and suicide in patients treated with isotretinoin. N. Engl. J. Med., 344:460.

17. Hull PR and Demkiw-Bartel C (2000): Isotretinoin use in acne: prospective evaluation of adverse events. J. Cutan. Med. Surg., 4: 66-70.

18. Rasochova E, Simaljakova M, Krocakova $J$ and Danielovicova $L$ (2004): Isotretinoin and mood change how is it with a Slovak population. J. Eur. Acad. Dermatol. Venereol., 2: 201-211.

19. Kaymak Y, Kalay M, Ýlter $N$ and Taner E (2006): Incidence of depression related to isotretinoin treatment in 100 Acne vulgaris patients. Psychological. Reports, 99: 897-906.

20. Hodgkiss-Harlow CJ, Eichenfield LF and Dohil MA (2009): Safety and adverse effects of isotretinoin in a pediatric dermatology clinical setting. $18^{\text {th }}$ Congress of the European Academy of Dermatology and Venereology. Berlin, pp: 7-11.

21. Nevoralova $Z$ and Dvorakova $D$ (2013): Mood changes, depression and suicide risk during isotretinoin treatment: a prospective study. Int. J. Dermatol., 52:163-168.

22. Ferahbas A, Turan MT, Esel E et al. (2004): A pilot study evaluating anxiety and depressive scores in acne patients treated with isotretinoin. J. Dermatolog. Treat., 15: 153-157.

23. Kellett SC and Gawkrodger DJ (2005): A prospective study of the responsiveness of depression and suicidal ideation in Acne patients to different phases of isotretinoin therapy. Eur. J. Dermatol., 15:484-488.

24. Hahm BJ, Min SU, Yoon MY and et al. (2009): Changes of psychiatric parameters and their relationships by oral isotretinoin in acne patients. J. Dermatol., 36:255-261.

25. Gnanaraj P, Karthikeyan S, Narasimhan $M$ and et al. (2015):
Decrease in Hamilton rating scale for depression following isotretinoin therapy in acne: an open-label prospective study. Indian. J. Dermatol., 60:461-464.

26. Kellett SC and Gawkrodgen DJ (1999): The psychological and emotional impact of Acne and the effect of treatment with isotretinoin. Br. J. Dermatol., 140: 273282.

27. Bozdag KE, Gulseren $\mathrm{S}$, Guven $\mathrm{F}$ and $\boldsymbol{e t}$ al. (2009): Evaluation of depressive symptoms in acne patients treated with isotretinoin. J. Dermatolog. Treat., 20: 293296.

28. Chia Y, Lane W, Chibnall J, Allen A and Siegfried E (2005): Isotretinoin therapy and mood changes in adolescents with moderate to severe acne: a cohort study. Archives of Dermatology, 141: 557-560.

29. Kaymak Y, Taner E and Taner Y (2009): Comparison of depression, anxiety and life quality in acne vulgaris patients who were treated with either isotretinoin or topical agents. International. Journal of Dermatology, 48(1):41-46.

30. Rehn LM, Meririnne E, Hook-Nikanne J and et al. (2009): Depressive symptoms and suicidal ideation during isotretinoin treatment: a 12-week follow-up study of male Finnish military conscripts. J. Eur. Acad. Dermatol. Venereol., 23:1294-1297.

31. Yesilova Y, Bez Y, Ari M et al. (2012): Effects of isotretinoin on obsessive compulsive symptoms, depression, and anxiety in patients with acne vulgaris. J. Dermatolog. Treat., 23: 268-271.

32. Marron SE, Tomas-Aragones $L$ and Boira S (2013): Anxiety, depression, quality of life and patient satisfaction in acne patients treated with oral isotretinoin. Acta. Derm. Venereol., 93:701-706.

33. Šimiæ D, Penaviæ J, Babiæ $D$ and Gunariæ A (2017): Pyschological status and quality of life in acne patients treated with oral isotretinoin. Psychiatr. Danub., 2:104-110.

34. Berg $M$ and Lindberg $M$ (2011): Possible gender differences in the quality of life and choice of therapy in acne. J. Eur. Acad. Dermatol. Venereol., 25:969-972. 